\title{
Making connections in aquatic ecosystems with acoustic telemetry monitoring
}

\author{
Michael R Donaldson $^{1 *}$, Scott G Hinch ${ }^{2}$, Cory D Suski ${ }^{1}$, Aaron T Fisk ${ }^{3}$, Michelle R Heupel ${ }^{4}$, and Steven J Cooke ${ }^{5}$
}

Autonomous acoustic telemetry monitoring systems have been deployed in aquatic ecosystems around the globe - from under ice sheets in the Arctic to coral reefs in Australia - to track animals. With tens of thousands of tagged aquatic animals from a range of taxa, vast amounts of data have been generated. As data accumulate, it is useful to reflect on how this information has advanced our understanding of aquatic animals and improved management and conservation. Here we identify knowledge gaps and discuss opportunities to advance aquatic animal science and management using acoustic telemetry monitoring. Current technological and analytical shortfalls still need to be addressed to fully realize the potential of acoustic monitoring. Future interdisciplinary research that relies on transmitter-borne sensors and emphasizes hypothesis testing will amplify the benefits of this technology.

Front Ecol Environ 2014; 12(10): 565-573, doi:10.1890/130283

$\mathrm{T}$ he complex ways in which animals move within and interact with the environment are fundamental to understanding both basic and applied aspects of their biology. While researchers were once limited to making inferences on movement and ecosystem interactions by observing animals visually or through mark-recapture studies, advances in telemetry provide researchers with near continuous, automated tracking of individuals across large spatial scales (Robinson et al. 2009). In aquatic ecosystems, where individuals are particularly difficult to observe, telemetry-based research has helped to reveal

\section{In a nutshell:}

- Acoustic telemetry monitoring is widely used in freshwater and marine ecosystems and has provided invaluable information on aquatic animals from various taxa and life stages

- Most acoustic telemetry monitoring studies focus strictly on animal movement, but this technology provides opportunities to take more integrative and comparative approaches to ask "big questions" in aquatic ecology

- Future telemetry-based studies should emphasize hypothesis testing and investigate more complex research questions to better understand how aquatic animals interact with their environment

- To maximize the information gained from acoustic telemetry monitoring, scientists must address existing technological, analytical, and data management needs

${ }^{1}$ Department of Natural Resources and Environmental Sciences, University of Illinois at Urbana, Urbana, IL * (michael.r.donaldson $@$ gmail.com); ${ }^{2}$ Center for Applied Conservation Research, Department of Forest Sciences, University of British Columbia, Vancouver, Canada; ${ }^{3}$ Great Lakes Institute for Environmental Research, University of Windsor, Windsor, Canada; ${ }^{4}$ Australian Institute of Marine Science, James Cook University, Townsville, Australia; ${ }^{5}$ Department of Biology, Institute of Environmental Science, Carleton University, Ottawa, Canada the ecology of a diverse range of taxa, including invertebrates, fish, amphibians, reptiles, birds, and mammals (Cooke et al. 2004).

The initial concept behind the development of acoustic telemetry monitoring technology was simple: design a low-cost, robust, autonomous telemetry receiver with an integrated hydrophone that could be deployed in aquatic systems to effectively track and study tagged animals (Panel 1). In the early 1970s, that concept was realized (Hawkins et al. 1974) and in subsequent years, the technology was refined and was embraced by the scientific community (Voegeli et al. 2001). Passive acoustic telemetry monitoring, hereafter referred to as acoustic monitoring, has become a mainstay in aquatic ecology; thousands of acoustic receivers now listen for tens of thousands of tagged animals in both freshwater and marine ecosystems across the globe (Heupel and Webber 2012). These individual, usually researcher- and question-specific, telemetry deployments (hereafter called nodes) have also been used to create informal or formal networks for collaboration and sharing of detection information between scientists. Strategic positioning of receivers and high-resolution spatial arrays has enabled largely automated detections across distances ranging from $<1 \mathrm{~m}$ to thousands of kilometers.

Here we reflect on the current state of acoustic monitoring research and identify key topics in aquatic science that benefit from this technique (Figure 1). Our intention is to focus on novel, contemporary studies that illustrate the state of knowledge on each of the identified research topics rather than providing a comprehensive literature survey. We discuss the limitations of acoustic monitoring (Panel 2) and identify technological (WebPanel 1) and analytical (WebPanel 2) needs that, if adequately met, would maximize returns. We also pose a number of questions to encourage integrative approaches and to stimulate thought (WebTables 1 and 2). New 


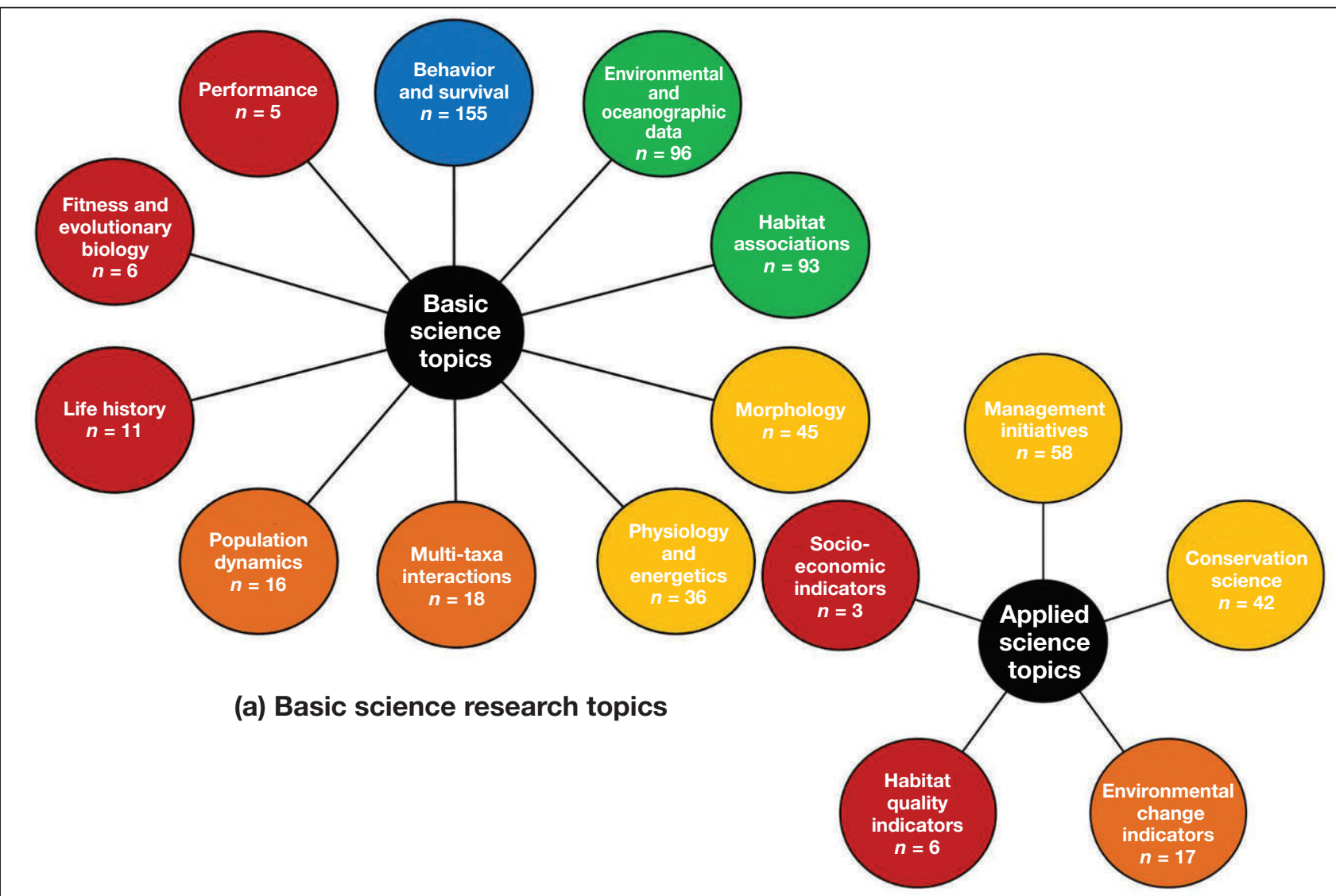

(b) Applied science research topics

Figure 1. Key acoustic telemetry monitoring research topics for (a) basic and (b) applied science. A heat map illustrates the number of published acoustic monitoring papers associated with each research topic (blue representing the most papers, red representing the least papers) based on keyword search returns using Web of Science. The combination of keywords began as ("acoustic network" or "acoustic telemetry" or "acoustic biotelemetry" or "acoustic tracking" or "acoustic biotracking") and was refined to "acoustic telemetry" or "acoustic tracking" and (network or array or monitoring). The resulting keywords were then further refined by each individual topic covered in the review to generate the numbers presented in the figure (eg for habitat quality indicators, the refined by topic included "habitat quality indicator" "habitat quality" or "habitat loss" or urbanization or degrad" or connectivity or "boat traffic" or "human activity" or spill or pollution).

directions for multidisciplinary studies are emerging, and researchers are currently on the verge of important new findings in the study of aquatic animals using acoustic monitoring.

\section{Individual-level responses}

\section{Behavior and survival}

The most common application of acoustic monitoring has been to study aquatic animal behavior and survival (eg Blumenthal et al. 2009; Jorgensen et al. 2010; Figure $1)$. Studies have helped to reveal seasonal and developmental changes in organism behavior (Andrews et al. 2010), and specially designed transmitter-receiver tags coupled with a receiver array have enabled explorations of group behavior and social interactions (Guttridge et al. 2010). A variety of migration behaviors have been examined, from juvenile salmon (Oncorhynchus nerka;
Figure 3) behavior and survival as they transition from freshwater rearing habitats to coastal Pacific Ocean waters (Welch et al. 2009), to movement behaviors of gray seals (Halichoerus grypus; Figure 4) in the northwestern Atlantic Ocean (Lidgard et al. 2012). Although much knowledge has already been gained, field-based acoustic monitoring applications have the potential to address emerging questions regarding animal behavior. For example, investigating behavioral anomalies, such as the presence of individuals outside their typical ranges, can provide information on migration behaviors and home ranges. Such findings may be particularly valuable in a climate-change context, given that the ranges of some species are expected to shift (Hampe and Petit 2005). Even a relatively small dataset can provide important insights, for example, into potential rarely observed offshore foraging behaviors of northern elephant seals ([Mirounga angustirostris]; Hayes et al. 2013), particularly when investigated with novel modeling techniques 


\section{Panel 1. Acoustic telemetry monitoring}

\section{Context}

Although various electronic tagging technologies exist (eg radio, satellite, archival), acoustic telemetry is designed specifically for use in aquatic ecosystems, including both marine and freshwater habitats (Figure 2). Acoustic receivers contain an integrated hydrophone that is submerged to detect transmissions via fixed position receivers for passive monitoring or by mobile receivers for active tracking.

\section{Acoustic transmitters}

Over several decades of refinement, acoustic transmitters have benefited from increased battery life and increasingly smaller transmitter sizes. Juvenile Salmon Acoustic Telemetry System (or JSAT) transmitters, for instance, measure only $12 \mathrm{~mm} \times 5 \mathrm{~mm} \times 4 \mathrm{~mm}$ and weigh $0.4 \mathrm{~g}$ in air (McMichael et al. 20l0). Transmitters can be implanted internally (Figure $3 \mathrm{a}$ ) or may be attached externally (Figure $3 \mathrm{~b}$ ), have uniquely coded identification numbers, and can be equipped with sensors to store or transmit information about the animal's internal and external environment. Novel technologies and sensors have been incorporated into transmitter design (eg combined acoustic trans-

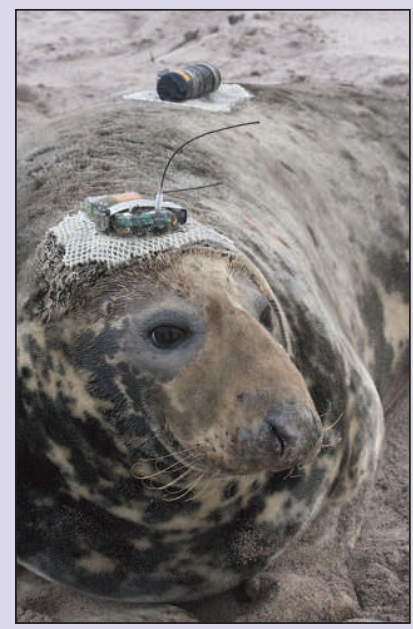

Figure 4. A gray seal (Halichoerus grypus) tagged with an acoustic transceiver used to detect other nearby tagged animals and a satellite transmitter used to track movements of the seal itself.

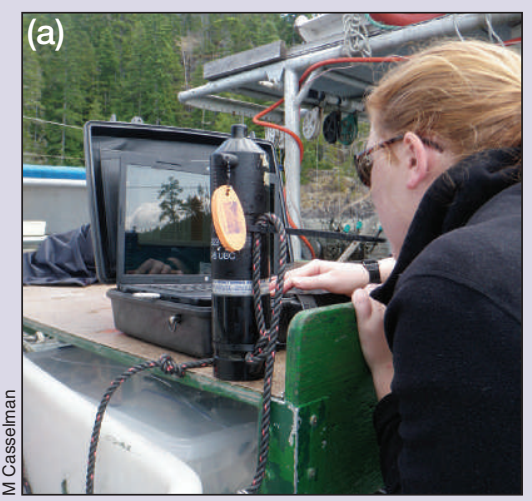
ceiver/GPS; Lidgard et al. 2012; Figure 4). New tracking approaches include Business Card Tags (Holland et al. 2009) that function as an animal-borne transmitter and receiver unit, which detects free-swimming individuals outside the confines of moored receivers but can also be incorporated into existing networks to expand detection coverage (Hayes et al. 20I3).

\section{Acoustic receivers}

Acoustic receivers are submerged in aquatic systems (Figure 5). A range of configurations can be used, including arrays of receivers orga-
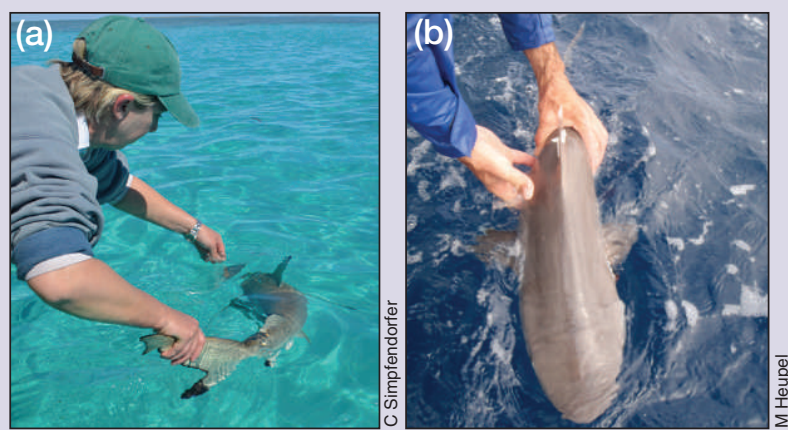

Figure 2. (a) A blacktip shark (Carcharhinus limbatus) and (b) a silvertip shark (Carcharhinus albimarginatus) being released following acoustic tagging.
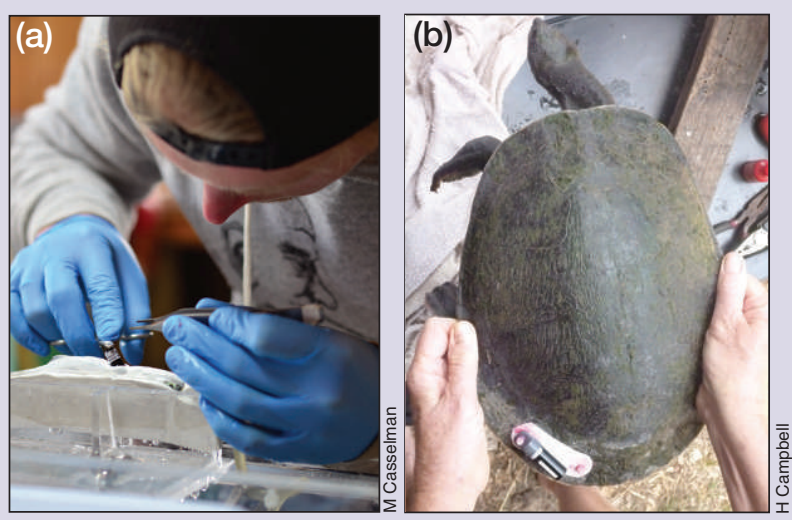

Figure 3. (a) An acoustic transmitter being surgically implanted into a juvenile sockeye salmon (Oncorhynchus nerka); (b) an acoustic transmitter externally attached to a Mary River turtle (Elusor macrurus).

nized in a grid formation (eg often used in systems such as lakes or bays) or lines of receivers deployed as a curtain (eg typically used along continental shelves, within riverine systems, or along key migration routes). Nodes can be small and geographically isolated or connected to much larger international networks such as the Ocean Tracking Network (OTN; Cooke et al. 20I I). Depending on the system being used, some acoustic receivers may be wired (ie cables attached to computers, such as Vemco [Halifax, Canada] Radio-linked Acoustic Positioning [VRAP] or Lotek Wireless Inc [Newmarket, Canada] MAP systems), others may be wireless but retrieved to download, while others still enable remote downloading to mobile computers through wireless technologies such as modems and Bluetooth ${ }^{\circledR}$.
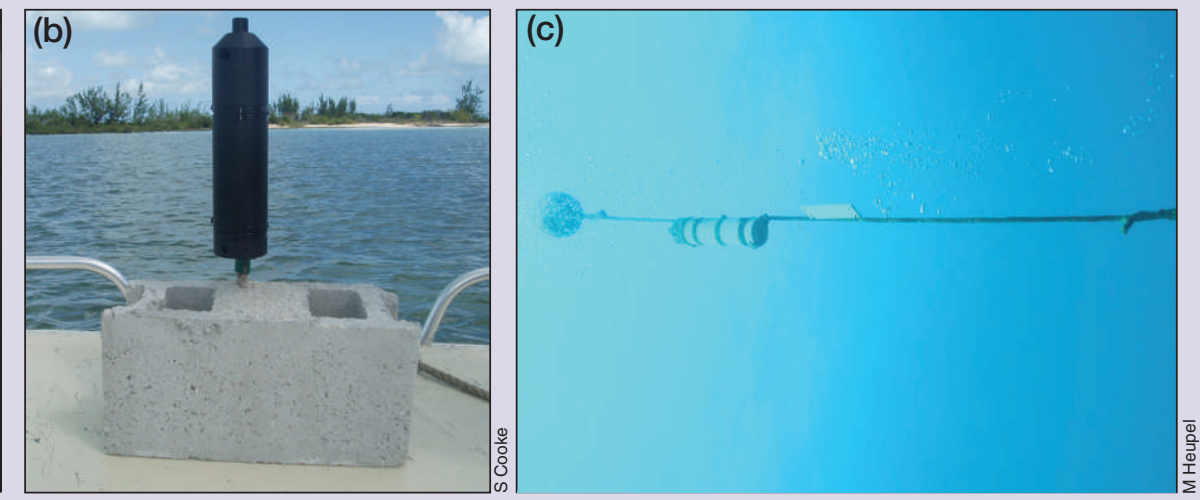

Figure 5. (a) An acoustic receiver being programmed prior to deployment in a coastal habitat in Canada; (b) an acoustic receiver attached to a mooring prior to deployment in a shallow tropical habitat in The Bahamas; (c) an acoustic receiver moored in a marine habitat in Australia. 
(WebPanel 2). Investigations into anomalous behaviors should be coupled with data on broader-scale, population-level patterns to avoid potentially misleading interpretations. Taking integrative approaches to animal behavior studies by combining multiple endpoints such as morphology, performance, and physiology (WebTable 1) will help provide context for movement data.

\section{Morphology}

Various measures of individual morphology and size are commonly included as covariates or factors in statistical analyses in acoustic monitoring research. Most studies collect only one measure of length and/or mass, but there are opportunities to take more detailed morphological measurements. Tagging typically requires animals to be restrained and handled during the tagging procedure, enabling researchers to make observations on the animals' physical condition (eg previous injuries or abnormalities) and to record more detailed body dimensions measurements using digital photography and imaging software (eg Hanson et al. 2007). Morphology can also be used to test hypotheses relating to fitness (eg Moland Olsen and Moland 2011; see "Life history" section below). Integrating morphology and allometry (the relationship of body size to shape) variables into acoustic monitoring studies could strengthen hypotheses related to predator-prey relationships (eg prey-size selection), habitat use (eg foraging site selection and competition), and morphology-based social hierarchies, as well as animal performance.

\section{Performance}

A range of remote-sensing options are now available to study animal movements in the field (Ropert-Coudert and Wilson 2005; Goldbogen et al. 2013). Acoustic monitoring allows for the near-continuous tracking of aquatic animal performance. For instance, acoustic tags equipped with sensors (eg pressure, acceleration, tailbeat frequency) have provided information on diving performance (eg the freshwater Arafura filesnake [Acrochordus arafurae]; Pratt et al. 2010), swimming speeds (eg Atlantic cod [Gadus morhua L]; Fernö et al. 2011), and tailbeat frequency (eg juvenile scalloped hammerhead sharks [Sphyrna lewini]; Lowe et al. 1998). Where researchers were previously required to conduct time-intensive and difficult manual tracking (Carey and Scharold 1990), large-scale telemetry nodes and networks now enable sophisticated and automated passive monitoring over larger spatial scales, using receiver curtains and high-resolution tracking, including three-dimensional telemetry arrays. Hanson et al. (2010) used a three-dimensional, whole-lake acoustic telemetry array with sub-meter accuracy to assess the swimming performance (ie daily distance traveled and mean daily swimming speed) of largemouth bass (Micropterus salmoides)

\section{Panel 2. Limitations of acoustic telemetry monitoring}

Despite the promise of acoustic telemetry monitoring as a tool to address emerging questions related to aquatic ecology, various limitations persist.

\section{Investigator handling and tagging effects}

For any aquatic telemetry study, wild animals typically must be captured, restrained, and handled in order to apply acoustic tags. Transmitters are often surgically implanted or attached externally (Figure 3), leading to concerns over anaesthetization and postsurgery healing and recovery. Transmitter retention can vary depending on the approach used and can be taxa-specific (Doody et al. 2009). These factors may limit acoustic telemetry monitoring, but several methods and approaches have been proposed to minimize tagging effects (eg rapid capture, careful handling, sterile surgical methods, experienced technicians; Cooke et al. 20l3b) and to account for surgical effects in experimental designs and analyses (eg Thiem et al. 20I I).

\section{Technological limitations}

Even with continued technological advancement and refinement, transmitters and receivers can fail or may have poor detection efficiencies. Several factors can influence transmitter detection efficiency, including failure of the transmitters, receivers, or batteries. Additional factors associated with detection efficiency include noise interference, water depth being too shallow (ie hydrophone exposed to air) or too deep (ie insufficient detection range), biofouling (eg mollusks attached to receivers can reduce performance; Heupel et al. 2008), water turbulence (Bergé et al. 20I2), and water quality (eg turbidity, conductivity, and salinity; Cooke et al. 20I3a). Careful layout of nodes is essential for obtaining quality monitoring data.

\section{Experimental design}

It has been difficult to establish control groups in telemetry studies that represent true baselines relative to some response variables. However, novel approaches in experimental design (eg comparative treatment groups; Donaldson et al. 2008) and more robust statistical approaches are helping to bridge this gap (Jacoby et al. 20I2).

\section{Species- or population-level inferences}

It can be difficult to infer population-level or species-level responses from data obtained from tagged individuals. Recent improvements in modeling approaches are beginning to resolve the problem of linking individual data to population-level outcomes (eg Perry et al. 20I0). 
over multiple seasons. Results obtained from acoustic accelerometer tags and flow-through respirometry (technique for estimating metabolic rate) in laboratory studies can be used to calibrate acceleration sensor tags to make correlations between acceleration and oxygen consumption and swimming performance (Wilson et al. 2013), which can then be applied to acoustic monitoring data from free-swimming individuals in field settings. Tags with depth sensors can facilitate examination of diving performance and foraging attempts in mammals (Lydersen 1991) and other species (eg snakes; Pratt et al. 2010).

\section{Physiology and energetics}

Acoustic monitoring provides a platform for taking the laboratory into the field in order to understand how animal physiology and energetics relate to behavior, ecology, and fitness in situ. The two most common methods of measuring physiological and energetic variables are through transmitter or animal-borne sensors or loggers, or by collecting biological samples (eg biopsies) at the time of transmitter attachment and relating that data to subsequent activity determined with telemetry. Sensors can measure activity or acceleration in near real-time and can be used to infer metabolic rate and energy expenditure (eg Lowe et al. 1998). Combining acoustic telemetry and physiological loggers will help in linking behavior with physiological parameters, such as heart rate (Block 2005). Biopsy approaches typically include the collection of blood or other tissue samples at the time of capture and transmitter attachment. Although the additional handling may further stress the target organism, biopsy methods are designed to be as rapid and non-invasive as possible to minimize these effects (Panel 2). Biopsy could enable integration of gene expression, biochemical processes, nutrition, stable isotopes, cellular responses, cardiovascular data, and toxicology data into acoustic monitoring studies, yet many of these research avenues have so far remained unexplored.

\section{Population-level responses}

\section{Population dynamics}

Given the characteristically small sample sizes in telemetry studies, it can be challenging to extrapolate results from individuals to populations for variables such as demography, recruitment, and productivity. However, statistical modeling approaches are continually improving inferences from telemetry studies at the population level. For example, Payne et al. (2011) used acoustic monitoring for a giant Australian cuttlefish (Sepia apama) with a highly male-biased sex ratio to quantify adult sex ratio (ASR) at the population level; these authors found that the ratio of breeding durations was equal to the operational sex ratio, suggesting a balanced ASR. The con- cept of using individual telemetry data to make population-level inferences has received recent attention in the literature (Panel 2; Perry et al. 2010).

\section{Fitness and evolutionary biology}

Fitness correlates, such as measurements of behavior and reproductive output (eg spawning aggregation behaviors of common snook [Centropomus undecimalis]; LowerreBarbieri et al. 2003) provided valuable, albeit indirect, insight into evolutionary outcomes when combined with acoustic monitoring. Acoustic monitoring is often used to assess survival, and an animal's fate can be used to elucidate fitness outcomes. By using acoustic telemetry to test hypotheses related to evolutionary biology, Moland Olsen and Moland (2011) identified a trade-off between body size and fisheries-harvest-induced selection in G morhua; the authors found that while natural selection favored large fish, commercial harvesters selectively removed them. Fishing mortality was considerably higher than natural mortality, providing evidence of how different mechanisms of selection can alter the fitness landscape.

\section{Life history}

Life-history traits, such as age of maturity, number and size of offspring, and growth and development rates, can be studied either directly or indirectly through acoustic monitoring. These topics typically require monitoring over longer durations, but are becoming more tractable with improvements in technology, specifically the miniaturization and improved longevity of acoustic tags. Understanding the early life history of aquatic animals is important for estimating survival, yet until recently there have been relatively few studies that focus on juvenile life stages relative to adults for most taxa (but see Heupel and Simpfendorfer 2002). The miniaturization of acoustic tags has provided information on the early life history of aquatic animals, including the timing of juvenile development and key events in their life history. For instance, McMichael et al. (2010) highlighted miniaturized acoustic tags, called the Juvenile Salmon Acoustic Telemetry system, which enable tagging of individuals $\sim 95 \mathrm{~mm}$ to study this early life stage.

\section{Ecosystem-level responses}

\section{Habitat associations}

The advent of satellite telemetry has been important for understanding how individuals interact with their habitats, but spatial and temporal imprecision have made it hard to study fine-scale movements relating to trophic ecology, habitat utilization, and interactions with conspecifics (Lidgard et al. 2012). Acoustic monitoring is immensely powerful for understanding ecosystem-level 
research questions because it can provide near-continuous monitoring of individuals at a fine scale (Espinoza et al. 2011). However, collecting quality data is dependent on strategic positioning of receivers and/or integration with technologies such as those associated with the global positioning system (GPS). Integration of such approaches is fundamental to asking complex research questions regarding aquatic habitat associations. For example, Furey et al. (2013) incorporated habitat variables, physicochemical conditions, and bathymetry (measurement of depth in a watery body) with acoustic monitoring to quantify estuarine habitat use by juvenile southern flounder (Paralichthys lethostigma). Acoustic monitoring has also been used to successfully identify home ranges and habitat use by ocean whitefish (Caulolatilus princeps; Bellquist et al. 2008), and to understand how habitats influence activity and behavior of reef sharks (eg Papastamatiou et al. 2009). Acoustic monitoring revealed the home range of juvenile hawksbill turtles (Eretmochelys imbricata) to be much larger than previously thought for developmental habitat at an atoll in Belize (Scales et al. 2011). Similar studies on sharks have provided information on site fidelity to specific habitats (Jorgensen et al. 2010).

\section{Inter-individual and multi-taxa interactions}

Innovative technologies such as Business Card Tags (BCTs) provide information on inter-individual and multi-taxa interactions, and help to address questions relating to trophic and other multi-species interactions. BCTs are animal-borne acoustic tags that also detect other acoustic-tagged animals (Hayes et al. 2013), provide information on interactions among tagged conspecifics (Holland et al. 2009), and could be applied to assess multi-taxa interactions. For example, Lidgard et al. (2012) equipped gray seals with BCTs and archival (ie logging) GPS telemetry units and were able to track spatially and temporally referenced associations between individuals and foraging habitats. Exploring hypotheses related to social interactions, social networks, and fine-scale animal behavior (ie personality; Krause et al. 2010) in the wild is an interesting area of research, and while acoustic monitoring has already provided information on such topics (eg Guttridge et al. 2010), BCTs could open up new avenues of research. Tagging individuals from different taxa with BCTs provides opportunities to investigate basic ecological relationships such as predator-prey associations, resource competition, and native-invasive species interactions. One could, for instance, tag individuals from a prey population with standard positional transmitters and tag individuals in a predator population with specially designed BCTs to track predation attempts. Fixed receiver nodes in key foraging areas would provide temporal and spatial information on predator-prey interactions.

\section{Integrating environmental data}

By using positional telemetry in combination with environmental, oceanographic, or meteorological datasets, researchers can investigate how abiotic conditions influence animal behavior, activity, and habitat associations. Acoustic monitoring studies have focused on responses of aquatic animals to changes in environmental conditions such as salinity and temperature (Ubeda et al. 2009), as well as ocean currents and wind (McMichael et al. 2013). Parameters related to weather events have also been investigated (eg Udyawer et al. 2013). Acoustic monitoring revealed that an extreme cold snap in the Everglades resulted in a high proportion of tagged juvenile bull sharks (Carcharhinus leucas) either permanently leaving their estuarine habitat or dying, leading to long-term demographic changes in the population (Matich and Heithaus 2012). Payne et al. (2013) used acoustic monitoring to show that, while the yellow-fin bream (Acanthopagrus australis) was most active during the day, rainfall coupled with changes in conductivity and turbidity resulted in a reversal of diel activity patterns. Childs et al. (2008) used acoustic monitoring to reveal that the abundance of spotted grunter (Pomadasys commersonnii) in a South African estuary was correlated with barometric pressure, wind direction, and sea temperature. With improved monitoring of environmental data as well as data-sharing capabilities between research groups, such information is becoming increasingly accessible, which should facilitate future integrative research. Incorporation of environmental data may also be fundamental to predicting and understanding how climate change influences individual-ecosystem interactions.

\section{Aquatic organisms as indicator species}

Aquatic vertebrates are often described as being indicator or sentinel species for ecosystem and human health (Bossart 2006). Tracking animals has great potential to directly monitor sentinel species (Block 2005). With the help of acoustic monitoring, they could potentially be used as environmental indicators for habitat quality or loss, degradation, or connectivity (eg Pecl et al. 2006), as well as for studying anthropogenic impacts, including boat traffic, chemical spills, or fisheries activities, on behavior and survival (Donaldson et al. 2012). For instance, it was found that juvenile hawksbill turtles were more abundant in a protected area habitat relative to unprotected habitat, likely due to superior quality habitat and/or protection from capture as bycatch in gill net fisheries (Scales et al. 2011). Acoustic-tagged sentinels could also act as indicators for environmental change, helping to document responses to climate regime shifts, extreme weather events, or ocean acidification, while temperature sensor tags or loggers could measure shifting micro-scale climatic changes and habitat associations over time. Aquatic organisms could 
potentially also be used as socioeconomic indicators for ecosystem services, monitoring of invasive species, fisheries catch monitoring, and ecotourism costs and benefits. Acoustic monitoring is increasingly being used in freshwater ecosystems, including the Laurentian Great Lakes (reviewed in Cooke et al. 2013a), enabling researchers to ask questions related to the valuable recreational and commercial fisheries that occur there.

\section{Conservation science}

An understanding of the general ecology of imperiled species - such as identifying breeding habitats (Paragamian et al. 2002) and quantifying survival during challenging life-history stages such as migration (Welch et al. 2009) - can be obtained through acoustic telemetry. Tracking the prey of imperiled species could also be important for understanding their behavior and habitat associations (eg to understand the foraging ecology of narwhal [Monodon monoceros], one could use acoustic monitoring to track Arctic cod [Arctogadus glacialis] and Greenland halibut [Reinhardtius hippoglossoides]). Simpfendorfer et al. (2010) relied on a series of telemetry techniques to track critically endangered juvenile smalltooth sawfish (Pristis pectinata) in southwest Florida to identify key habitats on which to focus conservation efforts, including shallow mud and sand banks and mangrove shorelines. The identification of discrete population structures using this technology could have important implications for vulnerable species or populations. For example, Jorgensen et al. (2010) combined satellite and acoustic tagging data with genetic analyses to show that eastern Pacific white sharks (Carcharodon carcharias) follow a persistent migration pattern consistent with genetically distinct populations. Acoustic monitoring can help to prioritize habitats to receive conservation efforts; this approach has recently garnered much attention with respect to establishing and monitoring Marine Protected Areas (Chapman et al. 2005). The same techniques can be integrated into new directions in conservation science, such as conservation physiology, an emerging conservation subdiscipline rooted in comparative physiology research (Metcalfe et al. 2012).

\section{@ Management}

Acoustic monitoring studies can inform management either directly (eg providing survival estimates related to fisheries bycatch; Donaldson et al. 2012) or indirectly (eg establishing baseline survival rates and population monitoring; Welch et al. 2009). Other management issues that could benefit from this approach include biological invasions (reviewed in Cooke 2008), fisheries operations (eg catch-and-release fisheries; Donaldson et al. 2008), and habitat management, particularly in a climatechange context. Acoustic tracking data can also be applied to the management of fish stocks, quotas, and management regions. As an example, an acoustic telemetry study on Greenland halibut (R hippoglossoides) provided evidence that individuals caught in the winter months by Inuit fisheries in Canada's Arctic were from the same population as those harvested to the south in the summer months, suggesting that the fisheries boundary should be adjusted; this result was expedited by acoustic monitoring as compared with traditional mark-recapture studies (Cooke et al. 2011). The management of highly migratory species and species with extensive transboundary ranges can also be enhanced, with potential relevance for ocean governance (VanderZwaag et al. 2013).

\section{- Conclusions}

Although most acoustic monitoring studies to date have focused exclusively on animal movement, several fundamental research questions remain unanswered. We have highlighted basic and applied research topics, provided key examples, and suggested subjects that warrant further inquiry. Numerous technological and data needs remain unfulfilled, but important innovations - for instance in data management and analysis - are opening new areas for research. Future investigations that integrate different tools and specialties, rely on transmitter-borne sensors, and emphasize hypothesis testing and experimentation will not only enhance acoustic monitoring applications but also help to address the unresolved questions identified in this paper.

\section{Acknowledgements}

Funding was provided by Natural Sciences and Engineering Research Council (NSERC) Strategic and Discovery grants and Ocean Tracking Network (OTN) and an NSERC Strategic Network grant. MRD was also funded by an NSERC postdoctoral fellowship. The concepts and ideas for future research suggested here were chiefly fostered by discussions at OTN Canada workshops. We thank H Campbell, M Casselman, D Lidgard, and C Simpfendorfer for providing photographs.

\section{References}

Andrews KS, Williams GD, and Levin PS. 2010. Seasonal and ontogenetic changes in movement patterns of sixgill sharks. PLOS ONE 5: e12549.

Bellquist LF, Lowe CG, and Caselle JE. 2008. Fine-scale movement patterns, site fidelity, and habitat selection of ocean whitefish (Caulolatilus princeps). Fish Res 91: 325-35.

Bergé J, Capra H, Pella H, et al. 2012. Probability of detection and positioning error of a hydro acoustic telemetry system in a fastflowing river: intrinsic and environmental determinants. Fish Res 125/126: 1-13.

Block BA. 2005. Physiological ecology in the 21st century: advancements in biologging science. Integr Comp Biol 45: 305-20.

Blumenthal JM, Austin TJ, Bothwell JB, et al. 2009. Diving behav- 
ior and movements of juvenile hawksbill turtles Eretmochelys imbricata on a Caribbean coral reef. Coral Reefs 28: 55-65.

Bossart GD. 2006. Marine mammals as sentinel species for oceans and human health. Oceanography 19: 134-37.

Carey FG and Scharold JV. 1990. Movements of blue sharks Prionace glauca in depth and course. Mar Biol 106: 329-42.

Chapman DD, Pikitch EK, Babcock E, and Shivji MS. 2005. Marine reserve design and evaluation using automated acoustic telemetry: a case-study involving coral reef-associated sharks in the Mesoamerican Caribbean. Mar Technol Soc J 39: 42-55.

Childs AR, Cowley PD, Næsje TF, et al. 2008. Estuarine use by spotted grunter Pomadasys commersonnii in a South African estuary, as determined by acoustic telemetry. Afr J Mar Sci 30: 123-32.

Cooke SJ. 2008. Biotelemetry and biologging in endangered species research and animal conservation: relevance to regional, national, and IUCN Red List threat assessments. Endang Species Res 4: 165-85.

Cooke SJ, Hinch SG, Wikelski M, et al. 2004. Biotelemetry: a mechanistic approach to ecology. Trends Ecol Evol 19: 334-43.

Cooke SJ, Iverson SJ, Stokesbury MJW, et al. 2011. Ocean Tracking Network Canada: a network approach to addressing critical issues in fisheries and resource management with implications for ocean governance. Fisheries 36: 583-92.

Cooke SJ, Midwood JD, Thiem JD, et al. 2013a. Tracking animals in freshwater with electronic tags: past, present and future. Anim Biotelemetry 1: 5 .

Cooke SJ, Nguyen VM, Murchie KJ, et al. 2013b. To tag or not to tag: animal welfare, conservation and stakeholder considerations in fish tracking studies that use electronic tags. J Int Wildlife Law Pol 16: 352-74.

Donaldson MR, Arlinghaus R, Hanson KC, and Cooke SJ. 2008. Enhancing catch-and-release science with biotelemetry. Fish Fish 9: 79-105.

Donaldson MR, Hinch SG, Raby GD, et al. 2012. Population-specific consequences of fisheries-related stressors on adult sockeye salmon. Physiol Biochem Zool 85: 729-39.

Doody JS, Roe J, Mayes P, and Ishiyama L. 2009. Telemetry tagging methods for some freshwater reptiles. Mar Freshwater Res 60: 293-98.

Espinoza M, Farrugia TJ, Webber DM, et al. 2011. Testing a new acoustic telemetry technique to quantify long-term, fine-scale movements of aquatic animals. Fish Res 108: 364-71.

Fernö A, Jørgensen T, Løkkeborg S, and Winger PD. 2011. Variable swimming speeds in individual Atlantic cod (Gadus morhua L) determined by high-resolution acoustic tracking. Mar Biol Res 7: 310-13.

Furey NB, Dance MA, and Rooker JR. 2013. Fine scale movements and habitat use of young of year southern flounder (Paralichthys lethostigma) in an estuarine seascape. J Fish Biol 82: 1469-83.

Goldbogen JA, Friedlaender AS, Calambokidis J, et al. 2013. Integrative approaches to the study of baleen whale diving behavior, feeding performance, and foraging ecology. BioScience 63: 90-100.

Guttridge TL, Gruber SH, Krause J, and Sims DW. 2010. Novel acoustic technology for studying free-ranging shark social behaviour by recording individuals' interactions. PLOS ONE 5: e9324.

Hampe A and Petit RJ. 2005. Conserving biodiversity under climate change: the rear edge matters. Ecol Lett 8: 461-67.

Hanson KC, Hasler CT, Suski CD, and Cooke SJ. 2007. Morphological correlates of swimming activity in wild largemouth bass (Micropterus salmoides) in their natural environment. Comp Biochem Physiol A 148: 913-20.

Hanson KC, Hasler CT, Donaldson MR, and Cooke SJ. 2010. Stability of swimming performance and activity hierarchies among wild largemouth bass (Micropterus salmoides) at multiple temporal scales: evidence for context-dependent shuffling between seasons. Can J Zool 88: 324-33.
Hawkins AD, MacLennan DN, Urquhart GG, and Rob C. 1974. Tracking cod Gadus morhua L in a Scottish loch. J Fish Biol 6: 225-36.

Hayes SA, Teutschel NM, Michel CJ, et al. 2013. Mobile receivers: releasing the mooring to "see" where fish go. Environ Biol Fish 96: 189-201.

Heupel MR and Simpfendorfer CA. 2002. Estimation of mortality of juvenile blacktip sharks, Carcharhinus limbatus, within a nursery area using telemetry data. Can J Fish Aquat Sci 59: 624-32.

Heupel MR and Webber DM. 2012. Trends in acoustic tracking: where are the fish going and how will we follow them? American Fisheries Society Symposium 76: Advances in fish tagging and marketing technology; 2008 Feb 24-28; Auckland, New Zealand.

Heupel MR, Reiss KL, Yeiser BG, and Simpfendorfer CA. 2008. Effects of biofouling on performance of moored data logging acoustic receivers. Limnol Oceanogr-Meth 6: 327-35.

Holland KN, Meyer CG, and Dagorn LC. 2009. Inter-animal telemetry: results from first deployment of acoustic "business card" tags. Endang Species Res 10: 287-93.

Jacoby DMP, Brooks EJ, Croft DP, and Sims DW. 2012. Developing a deeper understanding of animal movements and spatial dynamics through novel application of network analyses. Methods Ecol Evol 3: 574583.

Jorgensen SJ, Reeb CA, Chapple TK, et al. 2010. Philopatry and migration of Pacific white sharks. P R Soc B 277: 679-88.

Krause J, James R, and Croft D. 2010. Personality in the context of social networks. Philos T Roy Soc B 365: 4099-106.

Lidgard DC, Bowen WD, Jonsen ID, and Iverson SJ. 2012. Animal-borne acoustic transceivers reveal patterns of at-sea associations in an upper-trophic level predator. PLoS ONE 7: e48962

Lowe CG, Holland KN, and Wolcott TG. 1998. A new acoustic tailbeat transmitter for fishes. Fish Res 36: 275-83.

Lowerre-Barbieri SK, Vose FE, and Whittington A. 2003. Catchand-release fishing on a spawning aggregation of common snook: does it affect reproductive output? T Am Fish Soc 132: 940-52.

Lydersen C. 1991. Monitoring ringed seal (Phoca hispida) activity by means of acoustic telemetry. Can J Zool 69: 1178-82.

Matich P and Heithaus MR. 2012. Effects of an extreme temperature event on the behavior and age structure of an estuarine top predator (Carcharhinus leucas). Mar Ecol-Prog Ser 447: 165-78.

McMichael GA, Eppard MB, Carlson TJ, et al. 2010. The juvenile salmon acoustic telemetry system: a new tool. Fisheries 35: 9-22.

McMichael GA, Hanson AC, Harnish RA, and Trott DM. 2013. Juvenile salmonid migratory behavior at the mouth of the Columbia River and within the plume. Anim Biotelemetry 1: 14 .

Metcalfe JD, Le Quesne WJF, Cheung WWL, and Righton DA. 2012. Conservation physiology for applied management of marine fish: an overview with perspectives on the role and value of telemetry. Philos T Roy Soc B 367: 1746-56.

Moland Olsen E and Moland E. 2011. Fitness landscape of Atlantic cod shaped by harvest selection and natural selection. Evol Ecol 25: 695-710.

Papastamatiou YP, Lowe CG, Caselle JE, and Friedlander AM. 2009. Scale-dependent effects of habitat on movements and path structure of reef sharks at a predator-dominated atoll. Ecology 90: 996-1008.

Paragamian VL, Wakkinen VD, and Kruse G. 2002. Spawning locations and movement of Kootenai River white sturgeon. J Appl Ichthyol 18: 608-16.

Payne NL, Gillanders BM, and Semmens JM. 2011. Breeding durations as estimators of adult sex ratios and population size. Oecologia 165: 341-47.

Payne NL, van der Meulen DE, Gannon R, et al. 2013. Rain 
reverses diel activity rhythms in an estuarine teleost. $P$ R Soc $B$ 280: 20122363.

Pecl GT, Tracey SR, Semmens JM, and Jackson GD. 2006. Use of acoustic telemetry for spatial management of southern calamary Sepioteuthis australis, a highly mobile inshore squid species. Mar Ecol-Prog Ser 328: 1-15.

Perry RW, Skalski JR, Brandes PL, et al. 2010. Estimating survival and migration route probabilities of juvenile Chinook salmon in the Sacramento-San Joaquin River Delta. N Am J Fish Manage 30: 142-56.

Pratt KL, Campbell HA, Watts ME, and Franklin CE. 2010. Environmental and ecological factors influencing dive behavior in the freshwater snake Acrochordus arafurae: a field-based telemetric study. Mar Freshwater Res 61: 560-67.

Robinson WD, Bowlin MS, Bisson I, et al. 2009. Integrating concepts and technologies to advance the study of bird migration. Front Ecol Environ 8: 354-61.

Ropert-Coudert Y and Wilson RP. 2005. Trends and perspectives in animal-attached remote sensing. Front Ecol Environ 3: 437-44.

Scales KL, Lewis JA, Lewis JP, et al. 2011. Insights into habitat utilisation of the hawksbill turtle, Eretmochelys imbricata (Linnaeus, 1766), using acoustic telemetry. J Exp Mar Biol Ecol 407: 122-29.

Simpfendorfer CA, Wiley TR, and Yeiser BG. 2010. Improving conservation planning for an endangered sawfish using data from acoustic telemetry. Biol Conserv 143: 1460-69.

Thiem JD, Taylor MK, McConnachie SH, et al. 2011. Trends in the reporting of tagging procedures for fish telemetry studies that have used surgical implantation of transmitters: a call for more complete reporting. Rev Fish Biol Fisher 21: 117-26.

Ubeda AJ, Simpfendorfer CA, and Heupel MR. 2009. Movements of bonnetheads, Sphyrna tiburo, as a response to salinity change in a Florida estuary. Environ Biol Fish 84: 293-303.

Udyawer V, Chin A, Knip DM, et al. 2013. Variable response of coastal sharks to severe tropical storms: environmental cues and changes in space use. Mar Ecol-Prog Ser 480: 171-83.

VanderZwaag DL, Apostle E, and Cooke SJ. 2013. Tracking and protecting marine species at risk: scientific advances, sea of governance challenges. J Int Wildlife Law Pol 16: 105-11.

Voegeli FA, Smale MJ, Webber DM, et al. 2001. Ultrasonic telemetry, tracking, and automated monitoring technology for sharks. Environ Biol Fish 60: 267-81.

Welch DW, Melnychuk MC, Rechisky ER, et al. 2009. Freshwater and marine migration and survival of endangered Cultus Lake sockeye salmon (Oncorhynchus nerka) smolts using POST, a large-scale acoustic telemetry array. Can J Fish Aquat Sci 66: $736-50$.

Wilson SM, Hinch SG, Eliason EJ, et al. 2013. Calibrating acoustic transmitters for estimating energy use by wild adult Pacific salmon. Comp Biochem Phy A 164: 491-98.

\section{One-year Faculty Fellow in Environmental Studies (Aquatic Ecology) Colby College - Waterville, ME}

The Environmental Studies Program at Colby College invites applications for a one-year sabbatical replacement position in Aquatic Ecology to begin September 1, 2015. The successful candidate will have a specialization in the ecology of freshwater ecosystems along with an interest in the application of ecological principles to the solution of environmental problems. Applicants with experience and expertise in areas such as stream or river ecology, limnology, wetland ecology, ecosystem ecology, biogeochemistry, or the effects of humans or climate change on aquatic environments are especially encouraged to apply. Candidates should have a Ph.D. and a strong commitment to undergraduate education. Familiarity with liberal arts colleges and teaching experience is desirable. Teaching responsibilities will include two courses with laboratory (Aquatic Ecology and Global Change) and one additional intermediate-level course in the candidate's area of specialty. All courses will serve majors in the Environmental Studies Program, a strategic priority of the College. For more information about the Environmental Studies Program, faculty, and courses, please see the Program website at:

\section{www.colby.edu/environmentalstudies}

Interested candidates should submit a letter of application, curriculum vitae, statements of teaching philosophy and research interests, graduate transcript, three letters of recommendation, and a sample of current scholarship (e.g., a recent publication or manuscript) as PDFs to:

\section{ESaquaticecology@colby.edu}

Electronic submission of applications is required and receipt will be confirmed. Application review will begin January 5, 2015, and will continue until the position is filled. Inquiries may also be directed to:

\section{ESaquaticecology@colby.edu}

Colby College is a private, coeducational liberal arts college that admits students and makes personnel decisions on the basis of the individual's qualifications to contribute to Colby's educational objectives and institutional needs. Colby College does not discriminate on the basis of race, color, gender, sexual orientation, gender identity or expression, disability, religion, ancestry of national origin, age, marital status, genetic information, or veteran's status in employment or in our educational programs. Colby is an affirmative action/equal opportunity employer and operates in accordance with federal and state laws regarding non-discrimination.

For more information about the College, please visit our website:

www.colby.edu 